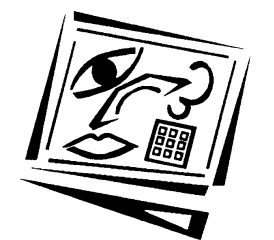

\title{
International design collaboration and mentoring for tertiary students through Facebook
}

\author{
Josh McCarthy \\ The University of Adelaide
}

\begin{abstract}
This study explores the efficacy of the online social networking site Facebook, for linking international digital media student cohorts through an e-mentoring scheme. It reports on the 2011 collaboration between the University of Adelaide in Australia, and Penn State University in the United States. Over one semester, twelve postgraduate students in Australia and ten undergraduate students in the United States took part in an online mentor scheme hosted by Facebook. Students were required to submit workin-progress imagery each week to a series of galleries within the forum. Postgraduate students from Adelaide mentored the undergraduate students at Penn State, and in turn, staff and associated industry professionals mentored the Adelaide students. Interaction between the two student cohorts was consistently strong throughout the semester, and all parties benefitted from the collaboration. Students from Penn State University were able to receive guidance and critiques from more experienced peers, and responded positively to the continual feedback over the semester. Students from the University of Adelaide received support from three different groups: Penn State staff and associated professionals; local industry professionals and recent graduates; and peers from Penn State. The 2011 scheme highlighted the efficacy of Facebook as a host site for e-mentoring and strengthened the bond between the two collaborating institutions.
\end{abstract}

\section{Project objectives and research participants}

This research has been carried out to evaluate the effectiveness of Facebook for establishing international networking opportunities for digital media students with peers and relevant industry professionals. Within this principal aim are the following objectives:

a. to establish the significance of mentoring in undergraduate and postgraduate digital media education;

b. to explore alternatives to traditional face to face mentoring;

c. to generate an engaging and interactive community linking digital media students with peers and industry.

This study involved final year postgraduate students enrolled in the Master of Design with Digital Media (MDDM) program at The University of Adelaide in Australia, and second year undergraduate students enrolled in the Interdisciplinary Digital Studio (IDS) program at Penn State University, in the United States. The two cohorts come from a broad range of educational backgrounds, including design studies, architecture and visual arts. 
The MDDM program is a postgraduate pathway for students within the undergraduate Design Studies, Computer Graphics, Computer Science, and Media programs at The University of Adelaide. Within the first semester of the program students explore a range of design fields specific to digital media through assignments and project work. Students are then expected to choose one area of design, such as graphic design, photography, animation, character design, or visual effects, to focus on for the rest of the program. Final Project in Design with Digital Media is the last 12-unit course to be completed within the program prior to graduation. This course allows students to devise their own project specific to the field of design they are working in. The course synopsis reads:

\begin{abstract}
This course comprises an individual or group culminating design, planning and / or research project that addresses an aspect of design, professional practice or design education in the context of digital media. Students will negotiate with the course coordinator a topic that reflects their own particular interests and the mode of digital and/or printed submission that is to be adopted. Theory covered includes the use of relevant design theory for the specialist topic of study. Opportunities for practical implementation of specialist concepts include the design and production of web sites, games, movies, simulations, interactive virtual worlds and other digital media productions according to the area of study in the negotiated proposal.
\end{abstract}

The IDS program at Penn State University introduces students to different areas of art and design with specific links to digital media. The program synopsis reads:

Digital technologies have been embraced by artists and designers in all areas,
expanding our capabilities to communicate and express far beyond traditional 2-D and
3-D media. Beyond simply enhancing speed and accuracy, their use is bringing
transformational change to the arts and design disciplines now free from physical
constraints and to the traditional boundaries between those disciplines. The Bachelor of
Design in Interdisciplinary Digital Studio (IDS) prepares students to explore, critically
appraise, and further push the boundaries of how emerging technologies are used.

Discussions between staff involved in the two institutions took place late in 2010 and it was decided that a collaborative international mentor scheme would take place in the first half of 2011. Final year students in the MDDM program at The University of Adelaide would mentor second year undergraduate students enrolled in the IDS program at Penn State University. Staff from Penn State University and associated industry professionals would in turn mentor the final year students in Adelaide. Due to similar schemes conducted in 2009 and 2010 (McCarthy, 2010), the final year students in Adelaide would also take part in a smaller local mentoring scheme throughout the semester.

The Penn State students involved in this scheme were exploring character and environmental design in the 3D graphics program Maya. This was their first look at the powerful software tool, whereas the final year students from Adelaide had several years' experience. In the 2011 scheme, students from each institution would submit work-in-progress, be it imagery, text or videos, to galleries in Facebook, within a new host 'page', and mentors would then log in the following week providing comments and critiques. It was expected that the new collaborative scheme would benefit all parties involved. Undergraduate students from Penn State University would benefit from constant feedback and critiques via more experienced students, while final year students from the University of Adelaide would benefit via critiques from international design staff and industry professionals. This group would also benefit from local mentors participating in the scheme. 


\section{Mentoring}

Mentoring has two basic functions in career development: instrumental and psychosocial. The first function, instrumental (or career enhancing), deals with jobrelated activities. Participants engaging as mentors in this function offer support, advice and information related to task, career or professional development. The second function, psychosocial (or interpersonal enhancement), has to do with polishing interpersonal work skills, reducing stress, talking about problems, discerning how one is perceived by one's colleagues, and role modelling correct behaviour for the workforce (Knouse, 2001). Mentoring can also be defined as a process of shared learning and growth that promotes mutual benefit, interaction and support for both parties (Bierema \& Merriam, 2002), and is becoming an increasingly important function for both entering the workforce and future career success (Knouse, 2001). The mentoring relationship is a two way process which potentially benefits both mentee and mentor as they learn from each other (Bierema \& Merriam, 2002). Recently a range of online mentoring approaches have been adopted in order to overcome barriers to traditional face to face mentoring, including lack of access due to geographical or professional isolation, and time constraints, the latter of which is of particular importance in the hectic, modern-day design industry.

\section{Online mentoring}

Online mentoring is carried out using electronic forms of communication, and is otherwise referred to as 'telementoring', 'e-mentoring' or 'virtual mentoring' (Kasprisin, Single, Single \& Muller, 2003). Asynchronous online mentoring is usually carried out by email, however recently synchronous methods of communication have been utilised more and more, including instant messaging, social network sites, online voice-to-voice networks, and video conference tools, such as Skype, indicating that the Internet and accompanying social software applications can provide a viable medium for enabling mentoring. Online mentoring is distinctive because it challenges the conventional wisdom that mentoring must be based on a personal, face to face relationship. It opens the possibility for relationships that cross boundaries of time, geography, gender and culture unlikely to happen with traditional mentoring relationships (Bierema \& Merriam, 2002). The ability of the Internet to overcome temporal and spatial barriers enables online or distance mentoring to have an unprejudiced quality that can be missing in face to face mentoring.

Social software appears to have affordances to support long term engagement of all parties in an e-mentoring relationship as it provides support for learning communities, dialogue and self-directed activity, while enabling group interaction and structured feedback processes. E-mentoring may happen between peers, one-on-one, one mentor may work with a team, or students may even provide mentoring to their mentors (Bierema \& Merriam, 2002). Mentors who may not have time for face to face meetings find telecommunications affords them the opportunity to still participate and share their expertise with young people (Goldman 1997); however, e-mentoring is not necessarily based on a wise elder dispensing advice and instruction to a protégé. Rather it is a mutually useful relationship that is highly versatile and can be adapted to work in a variety of settings (Bierema \& Merriam, 2002). E-mentoring assumes that a relationship exists between the mentor and mentee and that there is a mutual benefit for participating in the relationship. 
There has been some scepticism about the value of online mentoring. Brockbank and McGill (2006) believe the emphasis on online mentoring as a cheap and time-saving process results in a relationship that is driven by needs of the organisation, rather than the learning or developmental requirements of the mentee. Other researchers feel mentoring can only be carried out face to face so that mentees can observe their mentors (Evans \& Volery, 2001). On the other hand, advocates of online mentoring argue that it is effective, particularly when there are no opportunities for traditional, face to face mentoring. With Internet connections becoming faster and more widely accessible on a range of new platforms, the availability of mentoring becomes a national or even international option. This is particularly beneficial for people who would otherwise be unable to access mentoring opportunities locally (Kasprisin et al, 2003). However, while online mentoring creates new opportunities, it can involve additional costs and time, as developing websites and purchasing program software can be time consuming and costly processes. Kasprisin et al (2003) and Single and Single (2005) agree that online mentoring is not necessarily a time saving or a cheaper option to traditional mentoring and as such, finding existing platforms to use as host sites is an essential part of the process of establishing a successful e-mentoring scheme.

There are other disadvantages of the online medium that also need to be considered. Participation in this realm requires access to computer technology and computer literacy, and while these aspects of tertiary education are increasing dramatically, Prensky's 'Digital Natives' label (Prensky, 2001) doesn't accurately encapsulate the entire student population, particularly in remote areas. Intimacy can also be difficult to obtain through virtual communication. It is easier to misconstrue the message of an email as opposed to a face to face conversation, for example, as computer mediated communication lacks the extra cues of body language. On the other hand, emails provide a permanent record that can be returned to for further reflection. While ementoring overcomes the barrier of time constraints by allowing flexibility of participation, and asynchronous communication - emails can be read, considered and answered at a convenient time which allows contemplative reflection and constructive feedback (Stewart, 2006) - initial observations indicate that online relationships require additional support and education in the beginning stages of development. Ongoing communication and feedback are vital components of any successful mentoring relationship, but are of even greater magnitude with e-mentoring.

\section{Using Facebook as a host site}

Web 2.0 technologies including social networking sites such as Facebook and MySpace, and content-sharing sites such as YouTube and Flickr, allow individuals to present themselves, articulate their social networks, and establish or maintain connections with others. Social networking sites are amongst the most visited sites on the Internet, with 'Generation $-Y^{\prime}$ at the forefront of the popularity surge around the world. Facebook is the most used global social networking website with over 750 million active users as of 2011 (Facebook, 2011; Wikipedia, 2011). The site allows users to set up a profile page, including personal information, photos, videos, text, and a 'wall' for 'friends' to post information on. Users can add 'friends', create networks, pages, groups and events, and link to professional sites. By doing so, users can create an effective online presence. Users can also design and develop in-house applications that interact with core Facebook features. Facebook's popularity and the ability to generate new applications within the host site can make it a highly effective educational tool. 
Facebook was chosen as the host site for this research because of the uniform strength of its features as compared to other popular social networking sites such as MySpace and Friendster, the image-sharing site Flickr, and the open-source learning management system Moodle. The site's immense popularity ensured that a large number of students would already be familiar with its layout and operation, and would be comfortable utilising it during the semester, a most important factor in the choosing of a host site, given the potential for a 'digital divide' within the student cohort. Similarly, it was expected that students would be more inclined to participate in the learning environment and subsequent assessment if it was hosted by a site they already intended to visit repeatedly (McCarthy, 2010); this criterion told greatly against the use of LMSs, such as MyUni or Moodle, which would have resulted in an independent university site.

As Golder et al (2007) noted, many students entering tertiary education are already likely to be users of Facebook. One possible explanation as to why students find Facebook so compelling may lie in its 'one-stop-shop' nature (Duffy, 2011). Facebook is easily accessible - available to users for free and accessible from mobile forms of technologies, such as smart phones and tablet computers, through the advent of a sitespecific application. Its interface is intuitive and user friendly. Facebook allows users to create a complete online presence outlining their social networks, photo and video galleries, and opinions about recent events. Users can chat with friends, access countless built-in applications (and create their own), and maintain membership across a wide range of social, academic and professional interests. Many students are already using Facebook for their own purposes outside the classroom (and often in the classroom unrelated to their studies), and it is already very much integrated into their day-to-day practices. The 'group' and 'event' applications within Facebook enable the creation of an accessible, easily-maintained, and highly interactive online forum, while lastly, the $24 / 7$ availability of the site conforms with the 'anytime, anywhere' work attitude of Generation-Y students, as Krause et al (2005) note:

While we recognize that ICT use is by no means synonymous with engagement, the unique communicative capabilities of the technology as well as its increasingly

ubiquitous 'anywhere-anytime' qualities offer much to those seeking ways to optimize student engagement in the 21st century.

The benefits of online social networking within an academic framework are also evident in Krause's research as she notes that those students reporting the greatest level of satisfaction with their academic progress were typically the ones interacting with peers most regularly and in the widest range of social and academic contexts. Tynes (2007) highlights the psychosocial benefits of social networking sites, including the facilitation of identity exploration, the provision of social cognitive skills, and to fulfil students' needs for social support, intimacy and autonomy. Many academics (McCarthy, 2009; Tynes, 2007; Mazer, Murphy \& Simonds 2007) have found that 'social spaces' enable a more personal learning experience within online environments, with wikis, instant chat and messaging tools, and video conferencing of particular benefit for students. Mazer et al (2007) suggest that students respond positively towards a more 'professional' and 'interactive' website as opposed to the traditional static pages typically presented within a University site. They also indicate that the more personalised the social networking site's presence, the greater the motivation of students to participate and learn course material. 
The primary benefits of Facebook as a learning tool arise from its ability to enable students to share information, knowledge, and artefacts within a community and cocreative, dynamic network linked through members' personal profiles and the associations between them. The information in these profiles serves as links from which other network members with similar interests, communities, or latent ties can associate. The benefits of Facebook as a learning tool are clear given that learning is a social activity (Krause, 2005); social network sites with their powerful social affordances, have the capability to connect and engage students and to involve both students and teachers within new community and connected pedagogies (Duffy, 2011). The use of Facebook's comment feature stands as one of the primary educational benefits of the site, as Richardson (2006) suggests that the act of commenting on, responding to, or critiquing a peer's posts can initiate and promote analytical, as well as creative, instinctive, and associational thinking. The posting of online comments by students encourages them to engage with positions differing from their own (Duffy, 2011); the ability to create content for and present to a potentially global audience also creates more interest in the course material, within the student cohort. Table 1 outlines the potential learning opportunities afforded by Facebook in regards to the key graduate attributes of the two student groups (undergraduate students from Penn State University and postgraduate students from The University of Adelaide) associated with this research.

\section{Limitations of Facebook as a learning environment}

The possible risks and limitations of using Facebook as a learning tool need to be considered. Often technology is incorporated into pedagogy due to the popularity of the tool or application and its buzz-word status in mainstream, non-educational settings (Duffy, 2011). The rapid growth in popularity of social networking sites does not necessarily equate to immediate inclusion within the curriculum. Educators may even find resistance within the student cohort to use Facebook as a learning environment (Waycott, Bennett, Kennedy, Dalgarno \& Gray, 2010). It is important that new technologies are integrated into learning and teaching only when driven by pedagogy, rather than technology for technology's sake.

Student use of Web 2.0 social network sites has provoked a variety of response from teachers and educational institutions. Some schools have banned Facebook and blocked social networking sites from being accessed on campus while others have embraced the pedagogical benefits of the tools and advocate their use to enhance teaching, learning and assessment. Successful achievement of the possibilities of Web 2.0 social networking sites requires a thorough understanding of the potential barriers influencing acceptance of these technologies by educations and learners alike. The capabilities of such tools raise questions associated with copyright, privacy, and the role of the educator within the social networks. Some studies have suggested that the ways in which students use technologies in their everyday interactions with family and friends may often be different from their preferences for technology use in formal learning settings (Waycott et al, 2010). Salaway, Caruso and Nelson (2007) found that some students were concerned the use of online learning environments might 'eclipse valuable face-to-face interaction with instructors' (p13). Lohnes and Kinzer (2007) observed that some students were resistant to the use of such technologies in the classroom, when a student's use of a private laptop in class was seen as antisocial - 'a barrier to creating and maintaining the classroom community' (p3). While these factors need to be considered, the use of personal laptops within a design-based studio is 
nationally and internationally commonplace. In any design field students must be up to date with both contemporary software packages and online communication tools, and as such, computer based learning is an integral part of the student experience.

Table 1: Potential learning opportunities supported by Facebook

\begin{tabular}{|c|c|c|}
\hline \multirow{7}{*}{\begin{tabular}{l}
\multicolumn{1}{c}{ Group } \\
Undergrad- \\
uate student \\
attributes
\end{tabular}} & \multicolumn{2}{|r|}{ What Facebook technology provides } \\
\hline & $\begin{array}{l}\text { Strong visual } \\
\text { orientation }\end{array}$ & $\begin{array}{l}\text { Intuitive interface } \\
\text { Sharing of uploaded images } \\
\text { Sharing of uploaded videos }\end{array}$ \\
\hline & $\begin{array}{l}\text { Active learning } \\
\text { and student } \\
\text { centredness }\end{array}$ & $\begin{array}{l}\text { Opportunities for peer learning } \\
\text { Ability to critique and analyse peers' work } \\
\text { Interaction between students } \\
\text { Ownership of discussion forums } \\
\text { Opportunities for lifelong learning } \\
\text { Private and public communication via Facebook comment, chat } \\
\text { and message tools }\end{array}$ \\
\hline & $\begin{array}{l}\text { Engaging and } \\
\text { supporting } \\
\text { students }\end{array}$ & $\begin{array}{l}\text { Use of other social networking tools via embedded content and } \\
\text { links } \\
\text { Commenting on any design work by student and teachers } \\
\text { Confidence through an online voice for more reticent students } \\
\text { Availability of } 70 \text { languages supporting all international students } \\
\text { Constant and costly need for printing eliminated }\end{array}$ \\
\hline & Flexibility & $\begin{array}{l}\text { Anytime, anywhere access - via a range of devices } \\
\text { Immediacy of feedback }\end{array}$ \\
\hline & $\begin{array}{l}\text { Sense of } \\
\text { community }\end{array}$ & $\begin{array}{l}\text { Accounts created within a private teaching space } \\
\text { Student profiles showing name and portrait } \\
\text { Identity not anonymity } \\
\text { Interaction across the whole student cohort, specifically } \\
\text { interaction, both social and academic, between local and } \\
\text { international students }\end{array}$ \\
\hline & Privacy & $\begin{array}{l}\text { Students can control extended privacy settings regarding their } \\
\text { personal profiles } \\
\text { Students can 'add' friends at their own discretion }\end{array}$ \\
\hline $\begin{array}{l}\text { Postgrad- } \\
\text { uate student } \\
\text { attributes }\end{array}$ & $\begin{array}{l}\text { Strong visual } \\
\text { orientation }\end{array}$ & $\begin{array}{l}\text { Intuitive interface } \\
\text { Sharing of uploaded images } \\
\text { Sharing of uploaded videos }\end{array}$ \\
\hline & $\begin{array}{l}\text { Active learning } \\
\text { and student } \\
\text { centredness }\end{array}$ & $\begin{array}{l}\text { Opportunities for peer learning } \\
\text { Ability to critique and analyse peers' work } \\
\text { Opportunities for lifelong learning }\end{array}$ \\
\hline & $\begin{array}{l}\text { Engaging and } \\
\text { supporting } \\
\text { students }\end{array}$ & $\begin{array}{l}\text { Use of other social networking tools via embedded content and } \\
\text { links } \\
\text { Constant and costly need for printing eliminated }\end{array}$ \\
\hline & Flexibility & $\begin{array}{l}\text { Anytime, anywhere access - via a range of devices } \\
\text { Immediacy of feedback }\end{array}$ \\
\hline & $\begin{array}{l}\text { Professional } \\
\text { development }\end{array}$ & $\begin{array}{l}\text { Students can connect with relevant professionals and companies } \\
\text { Students can network with recent graduates and industry leaders }\end{array}$ \\
\hline & Performance & $\begin{array}{l}\text { Students improve performance via feedback and critiques from a } \\
\text { diverse, and potentially global, range of sources }\end{array}$ \\
\hline
\end{tabular}

As Cluett (2010) notes, launching a university presence on publicly available sites creates significant challenges and risks. Cyber-bullying and privacy, perhaps the most prevalent risks, can be dealt with using Facebook's administrative rules and toolsets. Page administrators (i.e. course coordinators) are granted simple and effective options for blocking and reporting users who mistreat others or who post offensive content. Similarly Facebook's terms and conditions, as well as the University's IT policy, ensure 
any such mistreatment is dealt with appropriately. Individual users (i.e. students and staff members) have access to extended privacy parameters that allow them to share and block any information they choose. Mazer et al (2007) suggest that Facebook can be a potential hazard for teachers and they need to be aware of what information they share online and how they present themselves in this global environment. The researchers highlighted three specific themes academics should address when using Facebook as an online learning tool:

1. Professionalism: "the appropriateness of the material on the teacher's Facebook website"

2. Students' "desires to learn more about the teacher": "Give information about your interests so students can get a better feel for your personality."

3. Students' "fear of potential negative treatment from teachers": "They should respect their student's privacy"; "Don't lecture the students about things you may come across on their profile." (Mazer et al, 2007)

Points 1. and 2. provide conflicting issues. While there is a common concern relating to the need to keep the personal aspects of a teacher separate from the academic aspects, researchers have found that students have a desire to learn more about their teachers. One way of accomplishing this is to create a 'teacher' profile separate from one's personal profile. It is very important for educators to be aware of everything that is accessible from their profile (information, photos, comments or status updates). Educators either need to maintain a professional 'personal' page for use within the online environment or keep a second page for academic use. This is directly linked to what information students choose to share with their teachers (point 3.) and the ways in which such information is to be shared. If not properly planned and considered this may lead to several problematic issues.

Duffy (2011) recommends that students are asked to create a 'limited profile' with controlled privacy settings if they choose to add their teacher as a 'friend'. By doing this, students need not show teachers their photos, videos, status updates, friends, posts or notes. This author, however, believes it is up to the student as an individual to make the decisions about what information they choose to share or block. It is also important to note that for a teacher and student to co-exist within a community in Facebook they do not even need to be Facebook 'friends'. Both parties can still communicate via the group or page of which they are members; they can both share information; photos and videos; and comment on each other's submissions. Furthermore both parties can still communicate via private emails (Facebook messages) should the need arise. Addressing these themes is the responsibility of the teacher and it is important to maintain a professional attitude when utilising this online environment, just as it is when teaching in a physical classroom.

The use of social media within education does not mean the role or attitudes of the teacher need to change. It is simply another tool which can be used to enrich the learning environment. The same can be said for 'cyber-bullying'. Bullying is not a new phenomenon brought into society with the introduction of social media. Social media simply provides a new platform for bullying to exist, just as it provides a new platform for supportive social and academic interaction. As has always been the case, it is the responsibility of the teacher to ensure that all students are informed of the terms and conditions that govern the classroom, be it physical or virtual, and that students are expected to engage with the course material and interact with their peers within these rules. 


\title{
Professional networking in digital media education
}

Feedback, critiques and interaction with peers and professionals are all essential elements of digital media education, particularly emergent specialist fields such as character modelling, rigging and animation. The industry moves forward at a great pace and it is vital students stay up to date with current practices and techniques. Often the best way to do this is to post work-in-progress media on online forums, such as CG Society, to receive feedback from industry professionals. Online social networking sites, such as Facebook, take this concept further by dynamically integrating academic and social qualities. The ability to chat online, engage and interact in a slightly less formal environment than a 3D-specific forum, allows a stronger social interaction to take place between the professional and student, mentor and mentee, or employer and prospective employee. As Hugh Nguyen, co-founder and producer of Adelaide-based animation company The People's Republic of Animation (the PRA) notes:

\begin{abstract}
A prospective employee not only has to have great technical ability, they need to fit into our company on a social level. As we are a fairly small studio and we all work together in the same room, it is crucial everyone gets along and works together. A site like Facebook allows you to gauge an understanding of someone before they even come into the office for an interview or some work experience. You can see their work, chat online and learn more about their personality - it's [Facebook] a very useful tool for an employer, and should be viewed as a very useful tool by students looking to enter the industry. (Interview with Hugh Nguyen, 2007)
\end{abstract}

In 2007, five graduates from the MDDM program at The University of Adelaide posted images and videos of work-in-progress on a publicly accessible group on Facebook, which was then viewed by two leading animation studios in Adelaide. As a result of this informal, online environment, the students were able to receive feedback, reviews and critiques from several professionals within the studios, resulting in discussion, networking, experience and ultimately, for three students, paid employment. This successful, albeit unstructured, process led to the consideration, and eventual integration, of a formal online mentoring scheme within the program in 2009.

\section{9 and 2010 case studies}

This online mentor scheme was established to improve the final year experience by linking students with relevant professionals and companies within the digital media industry. In 2009 and 2010 the online learning environment was used primarily to connect final year students with local and national industry mentors. Eighteen final year postgraduate coursework students enrolled in the MDDM program at The University of Adelaide took part in the study over one semester in 2009. The cohort was made up of ten male and eight female students and included nine international students and nine local students. The majority of students indicated they intended to move into the workforce, either locally, nationally or internationally, at the completion of the program, with a small number suggesting they would complete another postgraduate coursework program or commence doctoral studies. Bearing this in mind, it was essential to give the students the opportunity to a) network with relevant design industries; and b) develop a professional presence, while they were still studying.

The students were majoring in a diverse range of fields and as such a similarly wide range of mentors was required. As Long (2009) notes, a mentor program should 
establish a pool of mentors which promotes choice and flexibility for everyone participating. One mentor cannot be everything to a mentee, and as such, there was a need for 'collaborative mentoring' (Mullen, 2000). In total there were nineteen mentors involved in the project from both local and national design companies, representing the animation, visual effects, visualisation, web design, graphic design and advertising industries. The group included high and mid-level professionals as well as recent graduates from the program. All of those included in the study saw the scheme as a good opportunity to both scout for potential employees, and give something back to the community.

Permanent and casual staff involved in delivering the course also took part in the mentor scheme. The online mentor scheme was structured so that the cohort of students would have access to a range of mentors over the semester rather than having one set mentor per student. This decision was made in order to establish a sense of community within the group and to avoid any favouritism or the forming of small cliques. An unstructured nature to the role of the mentors also allowed for flexibility in terms of their responsibilities. By encouraging the mentors to provide critiques at any time, rather than a set day or week, it was hoped that they would then participate more regularly and significantly rather than feel like they only had a small window in which to make an impact. Students submitted work-in-progress images and videos each week for a total of ten weeks in the semester. The submissions were worth $10 \%$ of the students' final grade and were assessed on the quality of the submissions and accompanying descriptions. Industry representatives were asked to log on intermittently and supply feedback and critiques where suitable. Critiques came in the form of both written and pictorial responses.

The 2009 pilot study outlined many positive aspects and highlighted key areas that required revision to make the project more successful in future years. The scheme allowed students to receive feedback and critiques from a range of sources including current peers, recent graduates from the program, and leading local and national industry professionals. It also presented students with the opportunity to gain insight into various design professions while they were still studying and forge connections with possible future employers. A lack of structure to the scheme, however, ultimately weakened its success in several respects. Some mentors did not feel comfortable providing critiques, largely due to the lack of pre-existing relationships with students, so while it seems evident that mentoring is extremely important within digital media education, asynchronous online mentoring is not enough.

To tackle this issue in the future an introductory face to face session could be held at the start of the course, allowing mentors and mentees to meet in person and establish a preliminary connection, upon which an online relationship could be built. Video conferencing software, such as Skype, could also be employed to provide mentors and mentees with a preliminary connection if a face to face session is not possible. Facebook was seen as too informal by two students within the cohort and a change in host site may have been applicable, however the mentors were not concerned with this aspect. For the 2010 cohort, a reworked and more private Facebook group would be employed. Lastly, the scheme needed to be more structured in 2010 with a stronger synergy between the students' weekly submissions and the mentors providing critiques. In 2010 mentors would be assigned to each gallery based on their expertise, ensuring more relevant feedback and stronger participation from industry. 
The restructured online mentor scheme, within the MDDM program, in 2010 included an introductory session, prior to the commencement of classes, allowing students and mentors to meet face to face. The session included nine of the fifteen mentors involved in the scheme and all of the students (sixteen in total). In 2010, the mentors came from both local and national digital media companies, representing the animation, visual effects, graphic design and advertising industries. The group again included high and mid-level professionals, and also a larger ensemble of recent program graduates, many of whom participated in the 2009 study as students. As was the case in 2009, students were required to a) submit work-in-progress imagery and videos, to online galleries in Facebook every week; and - due to the success of the ungraded peer critiques in the 2009 study - b) provide comments on peers' submissions. Students were encouraged to provide constructive criticism within these comments, focusing on how their peers could improve their work. Industry mentors would then login to the site the following week and provide students with feedback, commentary and critiques. The mentors for each weekly gallery were chosen to complement the assessment tasks students faced throughout the semester. For example, at the start of semester when students were developing concept art and scripts for short films, mentors included artists and writers from the animation company, the PRA. Towards the end of semester, as students moved into post-production and marketing artwork, mentors from visual effects house Rising Sun Pictures were employed.

The 2010 experience was much more successful with a higher level of engagement from the mentors and much more feedback than was provided in 2009. Many students responded positively to the pictorial format of critiques provided by some mentors, as one student noted "images are much more useful than words". Once again, the majority of students indicated they believed social networking sites, such as Facebook, were helpful for linking with industry and establishing a professional online presence. Students appreciated the structured format of the scheme and the regular feedback that came from different industry representatives each week. There was no concern within the 2010 cohort regarding the suitability of Facebook as the host site. The use of Facebook as a professional tool grew significantly from 2009 to 2010, with students aware of the potential it provides, particularly in conjunction with other online tools such as Flickr, YouTube and Vimeo. The structured format of the scheme generated stronger and more consistent participation from all of the associated mentors in 2010. Each mentor was informed of their required involvement prior to the commencement of the semester and individually reminded before each weekly session. The mentors also appreciated the synergy between the students' weekly submissions and the choice of industry representatives for each gallery, as one mentor noted:

It was good to just be involved for one or two sessions. It helped that I only participated with the character performance sessions as this is my specialist area. Last year there were weeks where I provided some basic commentary, but minimal critical feedback as the submissions weren't in my area of expertise.

The two case studies from 2009 and 2010 suggested that such an online mentor scheme was suitable for any discipline that is dependent on digital content, provided the students are enthusiastic, the mentors willing, and the online platform capable of hosting the required media (McCarthy, 2010). In the 2010 scheme there was much more consistent feedback for all students from the mentors, largely due to the tightly structured program. Significantly, in 2010, there was less feedback from peers. This was due to both the increased feedback from mentors, and an unwillingness to provide critiques when an experienced mentor had already commented on the work: 
There wasn't a lot of feedback from peers. I think when you have the mentors commenting there's probably less desire to comment on your peer's work!

This was noted also by one mentor who had been a student in the scheme the previous year:

There was much less peer feedback this year by the look of it. That [peer feedback]

was a big positive last year.

Such discomfort was not evident in 2009, when there was less feedback from mentors, and it would be advantageous in future schemes to establish separate mentor-critique and peer-critique galleries. Both the 2009 and 2010 schemes have led to strong connections between mentor and mentee participants, including work experience and paid employment. After the success of the 2010 project, it was decided to expand the scheme to include an international collaborator, to allow students to connect with global industries and peers.

\section{The international mentor scheme in 2011}

After discussions late in 2010, it was decided that in 2011 the online mentor scheme in Facebook would expand through collaboration with Penn State University in the United States. This collaboration would improve already strong ties between the two institutions, building on past connections forged in a video conference-based design studio in 2007 (McCarthy, 2007). The new mentor scheme would focus on two of the key positives to emerge from the preceding two-year study - peer feedback from 2009, and professional networking from 2010. In 2011, final year postgraduate students from the University of Adelaide would mentor undergraduate students from Penn State University. Staff from Penn State and a group of industry representatives from both the United States and locally in Australia, would in turn mentor the Adelaide students. It was expected that final year students would gain valuable insight into industry in the United States, while undergraduate students from Penn State University would develop their skills and knowledge through engaging with more experienced peers.

Twelve final year postgraduate coursework students enrolled in the MDDM program at The University of Adelaide, and ten second year undergraduate students enrolled in the IDS program took part in the study during the first half of 2011. The students in Adelaide came from a predominantly design-based educational background and were majoring in fields such as animation, visual effects, film, and graphic design. The cohort was made up of eleven male students and only one female student, and included nine local and three international students. The Penn State University cohort was made up of seven male and three female students, all of whom were local students. The mentors involved in the 2011 scheme can be divided into three groups. Firstly the twelve final year students from Adelaide would be involved in mentoring the undergraduate students at Penn State University. Secondly there was a group of six locally-based industry mentors for the University of Adelaide students. Thirdly, staff from Penn State University and a small group of associated industry professionals would also act as mentors for the Adelaide students.

\section{The weekly submissions in 2011}

Students submitted work-in-progress images and videos each week for a total of ten weeks during the semester. In Adelaide, the submissions were worth $10 \%$ of the 
students' final grade for the twelve-unit course Final Project in Design with Digital Media. Students were assessed on the quality of their submissions and accompanying descriptions; as well as their comments and critiques for the Penn State submissions. The contributions from Penn State University students were also worth $10 \%$ of the final grade for their course. The image in Figure 1 shows a screen capture of a Penn State University student's video submission in week 8 in the 2011 mentor scheme. The submission resulted in the discussion between the student and Adelaide student mentors transcribed below. This discussion was representative of many interactions between the various students and mentors associated with the scheme during the semester.

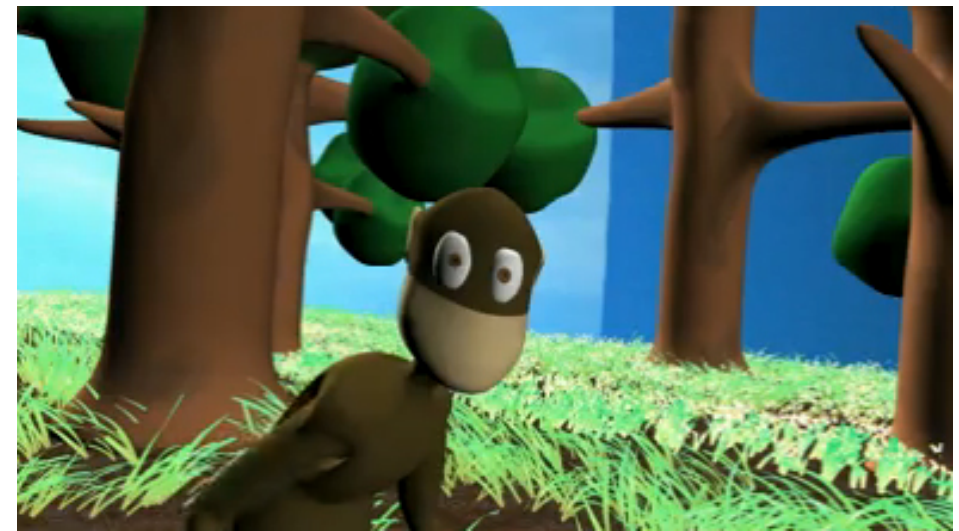

Figure 1: Screen capture of a Penn State University student's video submission in week 8 in the 2011 mentor scheme (see discussion between the student and Adelaide student mentors given below).

Submission by Penn State Student One (provided description of video):

This is my final project for A\&A210. It's a monkey who spots a banana and tries to get it, but doesn't.

Comment by Adelaide Mentor One:

Looks good, I like the monkey. The camera needs to be a little smoother and timed better. And with the blue background you should try use some kind of dome rather than a square because you can see the corner at 0:09 and it takes the focus off the monkey. Good work though, the grassy ground cover works well.

Reply from Penn State Student One:

Thanks for the criticism. Believe it or not, the background is a sphere, but the texture I used had the clouds placed on the bottom of the sphere, which I found weird. I'm not too great with camera movement, and I would love to work on this some more to get better transitions. I wanted to put this in after effects to give the animation a better feel, but I'm, definitely [going to] work with Maya cameras. Thanks for your crit.

Comment by Adelaide Mentor Two:

Hey [Penn State Student One], good first effort here. I'm glad that you're ready to put some effort into learning the cameras - it's a skill that a lot of people leave to the last minute and don't put a great deal of thought into, but can make or break a piece of work. Some things to consider: Check out some other walk cycles, yours is quite robotic here and some small changes can make a much more life-like and emotive walk. Secondly I think you're sitting on the fence with your textures - the grass is going toward realistic but the rest is quite matte and cartoonish. Don't be afraid to ditch realism in textures and focus on your animating! 
Reply from Penn State Student One:

Thanks [Adelaide Mentor Two]. I plan on improving on rigging and texturing over the summer. I used smooth bind to root the rig to the model and it seems to be the easiest. I want to try the other options to see if it will give more life-like movement to the model. Also with the grass, I used paint effects, which was more life-like. I originally planned on using the fur tool, but it looked plain to me. I was considering the cartoony look, but I guess I didn't know how to make the grass cartoon as well.

Comment by Adelaide Mentor Three:

Yeah, the grass stands out a bit too much, perhaps tone down the brightness, or make the strands of glass less apparent by making them smaller and less sharp, try to blend it in with the ground somehow. At the moment, the monkey is very similar to the trees and it's of a darker tone, whereas the grass is a very bright green and stands out and takes a lot of focus from the monkey.

Reply from Penn State Student One:

I see. I really didn't want to use the paint effects for the grass. I guess it also stands out because I used different types of grass as well. Thanks for the crit.

\section{The student experience}

A concluding survey outlined the attitudes of the students within the two cohorts towards the 2011 mentor scheme in Facebook. Students from the University of Adelaide were presented with five Likert-scale statements relating to two key topics: a) social network sites as professional tools, and b) the effectiveness of the online mentor scheme within the program. The students' collated responses are outlined in Table 2. Students from Penn State University were presented with a similar range of Likertscale statements relating to the feedback and critiques they received from their Adelaide-based mentors, and their attitudes towards Facebook as a professional development tool. The students' collated responses are outlined in Table 3. The questionnaires were designed and distributed in accordance with direction from the universities' Human Research Ethics Committees.

Table 2: Post-semester survey, MDDM program 2011, University of Adelaide students

\begin{tabular}{|l|c|c|}
\hline \multicolumn{1}{|c|}{$\begin{array}{c}\text { Post-semester survey statements } \\
\text { (12 out of 12 students took part in the survey) }\end{array}$} & $\begin{array}{c}\text { Mean response - } \\
\text { Likert scale 1-7 }\end{array}$ & $\begin{array}{c}\text { \% of students in } \\
\text { broad agreement }\end{array}$ \\
\hline $\begin{array}{l}\text { "I believe social network sites, such as Facebook, are beneficial } \\
\text { for academic critiques, discussion and networking." }\end{array}$ & 6.3 & $100 \%$ \\
\hline $\begin{array}{l}\text { "I believe social network sites, such as Facebook, are beneficial } \\
\text { for linking with relevant design industries." }\end{array}$ & 5.9 & $100 \%$ \\
\hline $\begin{array}{l}\text { "I believe social network sites, such as Facebook, are beneficial } \\
\text { for creating a professional online presence and improving } \\
\text { employment prospects." }\end{array}$ & 5.7 & $100 \%$ \\
\hline $\begin{array}{l}\text { "Over the course of the semester I received beneficial feed- } \\
\text { back and commentary from local industry representatives } \\
\text { through the online mentor scheme in Facebook." }\end{array}$ & 5.5 & \\
\hline $\begin{array}{l}\text { "Over the course of the semester I received beneficial } \\
\text { feedback and commentary from PSU staff and associated } \\
\text { professionals through the online mentor scheme in Facebook." }\end{array}$ & 5.1 & $75 \%$ \\
\hline $\begin{array}{l}\text { "Over the course of the semester I received beneficial } \\
\text { feedback and commentary from peers through the online } \\
\text { mentor scheme in Facebook." }\end{array}$ & 4.6 & \\
\hline
\end{tabular}


Table 3: Post-semester survey, MDDM program 2011, Penn State University students

\begin{tabular}{|l|c|c|}
\hline \multicolumn{1}{|c|}{$\begin{array}{c}\text { Post-semester survey statements } \\
\text { (7 out of 10 students took part in the survey) }\end{array}$} & $\begin{array}{c}\text { Mean response - } \\
\text { Likert scale 1-7 }\end{array}$ & $\begin{array}{c}\text { \% of students in } \\
\text { broad agreement }\end{array}$ \\
\hline $\begin{array}{l}\text { "Over the course of the semester I received beneficial } \\
\text { feedback and commentary from Adelaide University } \\
\text { students through the online Mentor Scheme in Facebook." }\end{array}$ & 6.6 & $100 \%$ \\
\hline $\begin{array}{l}\text { "I believe social network sites, such as Facebook, are bene- } \\
\text { ficial for academic critiques, discussion and networking." }\end{array}$ & 6.0 & $88 \%$ \\
\hline $\begin{array}{l}\text { "I believe social network sites, such as Facebook, are } \\
\text { beneficial for linking with relevant design industries." }\end{array}$ & 5.8 & $86 \%$ \\
\hline $\begin{array}{l}\text { "I believe social network sites, such as Facebook, are } \\
\text { beneficial for creating a professional online presence and } \\
\text { improving employment prospects." }\end{array}$ & 5.2 & \\
\hline
\end{tabular}

Despite a reduced scheme with local mentors, the Adelaide students appreciated the opportunity to receive critiques from local industry: "it was great to get advice on my designs from people already in the industry." Students also enjoyed the opportunity to network with staff and students in the United States: "it was awesome connecting with the PSU group. The leading VFX and animation companies are all based in the US, so it was good to make a few connections over there." The level of critiques and feedback received by the Adelaide students from the United States varied over the semester, however local mentors and peer-critique galleries ensured that feedback was always coming from at least one source:

... some weeks we didn't get much feedback from Penn State, but we had the local mentors as well which really helped out;" and "in the last couple of weeks it was about peer-critiques, everyone [the students] helping each other out to get the best result.

All of the students in Adelaide indicated they believed social network sites, such as Facebook, were valuable for linking with industry and establishing a professional online presence:

You need to set yourself up online in this industry and Facebook is a really easy way to do it. You can create a page, get followers, upload images and link to videos on YouTube.

The students from the Penn State University cohort also responded positively to the mentor scheme, citing constant, and often critical, feedback from their Adelaide student mentors:

There was some good in-depth discussions and sharing with the Adelaide students. I feel that it was a great idea that should indeed be built upon.

[The Adelaide student mentors] really helped out. Often you'd get different comments from four or five of them on the same video.

Students also saw the affordances of Facebook as an academic tool:

Instead of it being something I had to log onto, it showed up right next to everything else that I already see on my Facebook wall. It served as a constant reminder that I was participating in such a system, and streamlined my interaction with other students. On top of that, the casual atmosphere made it significantly easier to interact with the students on more of a peer level, than a teacher-pupil scenario.

I feel that using these interfaces really allows us to work in a format that is familiar, thus creating an easier workplace. I feel overall that a system like Facebook could be 
much easier in the long run even when compared to Penn State's ANGEL [Penn State's Course Management System].

Views were mixed when it came to linking with industry and creating a professional presence on Facebook. Some Penn State University students felt the site may not be viewed as legitimate by industry:

I would imagine that many "professionals" do not see Facebook as a legitimate area for artistic expression, discussion and critiques. This could be caused by our preconception of what Facebook is, or what we think it should be used for. This understanding could be changing as we speak! I do believe the argument in support of using networking sites for this type of academic work has merit.

While others believed it was both appropriate for professional development and effective for connecting with industry:

An online presence is definitely an important and beneficial aspect of the job application process. In these times where we are always connected, employers often will look online - and what's there really does represent you.

The networking value and "pseudo-portfolio" abilities definitely prove useful.

Overall the response to the scheme was positive, as staff and students from each institution were able to develop new professional and academic connections. One Penn State student also believed the scheme added strength to the IDS program, noting:

This was fun, and it gave us something original to work with. Systems like these can help us break apart from the masses of people flooding the digital media fields, and for lack of a better term, give us some bragging rights. While I cannot speak for the situation in Adelaide, I do know that PSU needs to add some legitimacy to the IDS program, and this is the type of education to do that.

\section{Discussion}

The 2011 case study suggested that Facebook was a strong host site for the collaborative international mentor scheme between the University of Adelaide and Penn State University. Interaction between the two student cohorts was consistently strong throughout the semester, and all parties benefitted from the collaboration. Students from Penn State University were able to receive guidance and critiques from more experienced peers, and responded positively to the continual feedback over the semester. Students from the University of Adelaide received support from three different groups: Penn State staff and associated professionals provided critiques in the international mentor scheme; industry professionals and recent graduates provided critiques in the local mentor scheme; and peers from both Adelaide and Penn State provided feedback within both schemes. The mentor scheme in 2011 strengthened the bond between the two institutions and future collaborations are expected. Students from both the University of Adelaide and Penn State University have continued to submit work to the Facebook page since the completion of the associated courses, suggesting the connections forged between the two cohorts will continue in the future as well.

The three year study in the MDDM program provided much insight into the use of Facebook as a learning environment for industry and peer mentoring in digital media education. The 2009 pilot study showed that the scheme allowed students to receive 
feedback and critiques from a range of sources including current peers, recent graduates from the program, and leading local and national industry professionals. One of the most positive outcomes from the scheme was the peer support within the cohort. Students provided each other with critiques over the semester allowing students to gain valuable feedback from multiple sources, rather than just one or two industry professionals. It also presented students with the opportunity to gain insight into various design professions while they were still studying and forge connections with possible future employers, seen by the students as a crucial factor for future success. The revised scheme in 2010 provided a more structured framework and as a result there was more consistent feedback for all students from the mentors. At least two mentors provided critiques to each student every week, resulting in long online discussions and significant networking opportunities for the cohort. While the mentor critiques improved in 2010, the peer feedback dropped off, suggesting there should be separate mentor-critique and peer-critique galleries. The 2011 case study outlined that Facebook was suitable to host collaborative mentor projects between international partners.

In recent years several online mentoring approaches have been explored and adopted in order to overcome barriers to traditional face to face mentoring. Such barriers include lack of access due to geographical or professional isolation, and time constraints, the latter of which is of particular importance in the hectic, modern-day design industry. Often industry professionals simply don't have the time to regularly meet face to face with students. Online tools enable mentoring to take place despite this, as professionals can interact with their mentees in both synchronous (online chat, video conferencing) and asynchronous (email, social networking sites via comment systems) ways, without leaving the office. Facebook is able to support long term engagement of all parties in an online mentoring relationship, as it provides support for learning communities, dialogue and self-directed activities while enabling group interaction and structured feedback processes.

The online environment in Facebook gave mentors the opportunity to scout for and connect with prospective employees. Mentors could view the quality of students' work; see how they responded to the provided feedback; and ascertain whether they had the potential to work within their company. Many mentors also relished the opportunity to both give something back to the industry, and be involved in the education of future designers.

The three year study in the MDDM program has shown that Facebook is highly effective for linking final year students with industry professionals. The site has proven to be effective due to a) its popularity with students and design professionals; b) its intuitive interface, ease of use, and accessibility; c) the provision of a platform for both synchronous and asynchronous forms of mentoring; and d) the provision of a platform for students to establish a professional online presence. Other Web 2.0 technologies, such as Twitter, YouTube and Flickr, can all be integrated into the same page, hosted by Facebook, creating a complete professional package, suitable for online showreels and folios. To reiterate a comment from a 2011 Adelaide student:

You need to set yourself up online in this industry and Facebook is a really easy way to do it. You can create a page, get followers, upload images and link to videos on YouTube. (2011 Adelaide student) 


\section{Conclusion}

The 2011 case study in the MDDM program outlined many positives to emerge from the partnership between the University of Adelaide and Penn State University. Students were able to connect with their global peers, and learn from international industry professionals, while improving their own work via feedback from an evergrowing number of sources. Based on the research from 2009 to 2011, the following eight recommendations have been established for using Facebook as the host site for an online mentor scheme for final year education:

- Provide a broad range of mentors, including recent graduates, mid-level professionals and industry leaders.

- Promote 'group mentoring' and avoid individual, or 'one-on-one', mentor/ mentee relationships.

- Use a structured program of mentors throughout the course, linking specific mentors to the weekly tasks or assignments.

- Encourage peer critiques in addition to mentor critiques.

- Use separate galleries for mentor critiques and peer critiques.

- Link the Facebook group (or page) to relevant professional pages and sites within, and external to, Facebook.

- Use the Facebook group (or page) to show exemplars of student work throughout the semester.

- Use the online learning environment to connect with national and international partners.

While these recommendations have been established based on case studies involving digital media programs, they are applicable to other disciplines as well. The online learning environment in Facebook lends itself to any discipline which is reliant on digital content, such as images, text and videos. The ability to provide and receive constant feedback throughout a project can help improve a student's understanding of the subject, and subsequently improve their academic performance and development. This in turn supports progression through courses and programs, and eventually into the workforce.

\section{Outcomes of the research from 2009 to 2011}

- The three year study in the MDDM program helped determine the requirements and expectations of final year postgraduate design students as they prepare to enter the workforce. Key expectations included a) connections with industry, through professional networking, real projects and clients, and feedback from industry professionals; b) appropriate facilities, including hardware and software; and c) feedback from a range of sources including staff, industry leaders, recent graduates and peers.

- The online learning environment in Facebook dynamically integrated academic and social qualities, and allowed students to connect with industry and present themselves to potential employers.

- The online environment enabled busy, and often remote, professionals to participate in the mentor scheme through interacting with their mentees via both synchronous and asynchronous forms of communication.

- The mentor scheme in Facebook from 2009 and 2011 generated an engaging and interactive community linking students with industry. 
- The 2009 study outlined that the scheme allowed students to receive feedback and critiques from a range of sources including current peers, recent graduates from the program, and leading local and national industry professionals.

- In the 2010, the structured scheme allowed for more consistent feedback for all students from the mentor group. At least two mentors provided critiques to each student every week, resulting in long online discussions and significant networking opportunities for the cohort.

- The 2011 case study outlined that Facebook was suitable to host collaborative mentor projects between international partners.

- Through the scheme, students were able to establish a professional online presence. Other Web 2.0 technologies, such as Twitter, YouTube and Flickr, were integrated into the same host page in Facebook, creating a complete professional package, suitable for online showreels and folios.

- The mentor scheme in Facebook from 2009 and 2011 helped improve students' academic performance within the program by facilitating the provision of consistent feedback from industry professionals, staff and peers throughout the semester.

- Students improved their awareness and insight into industry, gained valuable feedback and critiques from a range of sources, and networked with potential employees.

- In 2011 students from the University of Adelaide and Penn State University generated strong connections and gained insight into global design industries.

- The local mentor schemes from 2009 and 2011 led to strong connections between mentors and mentees, resulting in work experience and employment for several student participants at the completion of the course

Within the MDDM program, the online environment in Facebook helped establish a framework for an evolving and expanding community of students, recent graduates and industry leaders, to promote professional networking. Given the global nature of the design industry, there is a strong need to connect with peers and industry leaders around the world. Design firms now actively source potential employees through online networking tools such as Facebook, forums and blogs, reinforcing the validity of incorporating such communicative tools into current curriculum. The opportunities for national and international collaboration are limitless, at both university and industry levels. Students seeking advice and mentoring are no longer limited to their immediate geographical location, and similarly, companies can discover and establish connections with potential employees all over the world.

\section{References}

Alexa, The Web Information Company (2011). http: / / www.alexa.com/

Bargh, J. A., McKenna, K. Y. A. \& Fitzsimons, G. M. (2002). Can you see the real me? Activation and expression of the "true self" on the Internet. Journal of Social Issues, 58(1), 33-48. http: / / dx.doi.org/ 10.1111/1540-4560.00247

Bierema, L. \& Merriam, S. (2002). E-mentoring: Using computer mediated communication to enhance the mentoring process. Innovative Higher Education, 26(3), 211-227. http: / / dx.doi.org/10.1023/ A:1017921023103

Brockbank, A. \& McGill, I. (2006). Facilitating reflective learning through mentoring and coaching. London: Kogan Page. 
Cluett, L. (2010). Online social networking for outreach, engagement and community: The UWA Students' Facebook page. In Educating for sustainability. Proceedings of the 19th Annual Teaching Learning Forum, 28-29 January 2010. Perth: Edith Cowan University. http: / / otl.curtin.edu.au/tlf/tlf2010/ refereed/cluett.html

Compete (2011). http: / www.compete.com/

Duffy, P. (2011). Facebook or Faceblock. In M. J. W. Lee \& C. McLoughlin (Eds), Web 2.0 based elearning: Applying social informatics for tertiary teaching. pp284-300. Hershey, PA: IGI Global.

Evans, D. \& Volery, T. (2001). Online business development services for entrepreneurs: An exploratory study. Entrepreneurship and Regional Development, 13(4), 333-350. http: / / dx.doi.org/10.1080/08985620110052274

Facebook (2011). http: / / www.facebook.com/

Golder, S., Wilkinson, D. \& Huberman, B. (2007). Rhythms of social interaction: Messaging within a massive online network. In C. Steinfield, B. Pentland, M. Ackerman \& N. Contractor (Eds), Proceedings of Third International Conference on Communities and Technologies. London: Springer. http: / / www.hpl.hp.com/research/idl/papers/facebook/facebook.pdf

Goldman, M. (1997). Perspective on telementoring and mentor center. National School Network Telementoring $\mathcal{E}$ Mentor Center. [verified 23 Apr 2012] http: / / alpha.musenet.org:81/telementor_wrkshp/goldman.html

Kasprisin, C. A., Single, P. B., Single, R. M. \& Muller, C. B. (2003). Building a better bridge: Testing e-training to improve e-mentoring programmes in higher education. Mentoring and Tutoring, 11(1), 67-78. http:/ / dx.doi.org/10.1080/1361126032000054817

Knouse, S. B. (2001). Virtual mentors: Mentoring on the Internet. Journal of Employment Counselling, 38(4), 162-169. http:/ / dx.doi.org/10.1002/j.2161-1920.2001.tb00498.x

Krause, K. (2005). The changing student experience: Who's driving it and where is it going? Keynote paper presented at Student Experience Conference: Good Practice in Practice, 5-7 September, Charles Sturt University, Wagga Wagga, NSW.

http:/ / www.griffith.edu.au/__data/assets / pdf_file/0003/39270/StudExpKeynote05.pdf

Krause, K., Hartley, R., James, R. \& McInnis, C. (2005). The first year experience in Australian universities: Findings from a decade of national studies. Canberra: DEST. http:/ / www.dest.gov .au/sectors/higher_education/publications_resources/profiles / first_year_experience.htm

Krause, K. (2005). Serious thoughts about dropping out in first year: Trends, patterns and implications for higher education. Studies in Learning, Evaluation, Innovation and Development, 2(3), 55-68. http: / / sleid.cqu.edu.au / include/ getdoc.php?id=342\&article=84\&mode=pdf

Lohnes, S. \& Kinzer, C. (2007). Questioning assumptions about students' expectations for technology in college classrooms. Innovate, 3(5). http:/ / www.innovateonline.info/ pdf/ vol3 issue5/Questioning_Assumptions_About_Students\%27_Expectations_for_Technology_in_C ollege_Classrooms.pdf

Long, J. (2009). Assisting beginning teachers and school communities to grow through extended and collaborative mentoring experiences. Mentoring $\mathcal{E}$ Tutoring: Partnership in Learning, 17(4), 317-327. http: / / dx.doi.org/10.1080/13611260903284390

Mazer, J. P., Murphy, R. E. \& Simonds, C. J. (2008). I'll see you on Facebook: The effects of computer-mediated teacher self-disclosure on student motivation, affective learning and classroom climate. Communication Education, 56(1), 1-17. http: / / www.tandfonline.com/ doi / full / 10.1080/03634520601009710\#tabModule

McCarthy, J. (2010). Connected: Linking postgraduate students and industry through online mentoring. On the edge: Cross-disciplinary and intra-disciplinary connections in architectural science. Proceedings ANZAScA Conference. Auckland, July 2010. 
McCarthy, J. (2007). Digital design and student learning through videoconference collaboration. In ICT: Providing choices for learners and learning. Proceedings Ascilite Singapore 2007. http:/ / www.ascilite.org.au/conferences/ singapore07/procs/ mccarthy.pdf

McLoughlin, C. \& Lee, M. J. W. (2008) The three P's of pedagogy for the networked society: Personalization, participation, and productivity. International Journal of Teaching and Learning in Higher Education, 20(1), 10-27. http: / / www.isetl.org/ijtlhe/ pdf/IJTLHE395.pdf

Mullen, C. (2000). Constructing co-mentoring partnerships: Walkways we must travel. Theory Into Practice, 39(1), 4-11. http:/ / www.jstor.org/ discover/10.2307/1477435

Nguyen, H. (2007). Hugh Nguyen: Interview by Josh McCarthy.

Prensky, M. (2001), Digital natives, digital immigrants. On The Horizon, 9(5). http: / / www.marcprensky.com/writing/prensky\%20$\%$ 20digital $\%$ 20natives, $\%$ 20digital $\% 20$ immigrants $\% 20-\% 20$ part1.pdf

Rambe, P. (2012). Critical discourse analysis of collaborative engagement in Facebook postings. Australasian Journal of Educational Technology, 28(2), 295-314. http: / / www.ascilite.org.au/ajet/ajet28/rambe.html

Richardson, W. (2006). Blogs, wikis, podcasts, and other powerful tools for classrooms. Thousand Oaks, CA: SAGE.

Salaway, G., Carusio, J. \& Nelson, M. (2007). The ECAR study of undergraduate students and information technology, 2007. Boulder, Colorado: EDUCAUSE Center for Applied Research. http:/ / www.educause.edu/ers0706

Single, P. B. \& Single, R. M. (2005). E-mentoring for social equity: Review of research to inform program development. Mentoring and Tutoring, 13(2), 301-320. http: / / dx.doi.org/10.1080/13611260500107481

Stewart, S. (2006). A pilot study of email in an e-mentoring relationship. Journal of Telemedicine and Telecare, 12(3), 83-85. http:/ / dx.doi.org/10.1258/135763306779380011

Tidwell, L. C. \& Walther, J. B. (2002). Computer-mediated communication effects on disclosure, impressions, and interpersonal evaluations: Getting to know one another a bit at a time. Human Communication Research, 28(3), 317-348. http: / / dx.doi.org/10.1111/j.14682958.2002.tb00811.x

Tynes, B. M. (2007). Internet safety gone wild?: Sacrificing the educational and psychosocial benefits of online social environments. Journal of Adolescent Research, 22(6), 575-584, http: / / dx.doi.org/ 10.1177/ 0743558407303979

Waycott, J., Bennett, S., Kennedy, G., Dalgarno, B. \& Gray, K. (2010). Digital divides? Student and staff perceptions of information and communication technologies. Computers $\mathcal{E}$ Education, 54(4), 1202-1211. http: / / dx.doi.org/10.1016/j.compedu.2009.11.006

Wikipedia (2011). Facebook http: / / en.wikipedia.org/wiki / Facebook

Author: Josh McCarthy, Lecturer

School of Communication, International Studies and Languages

Magill Campus, The University of South Australia

Email: josh.mccarthy@unisa.edu.au Web: http: / / people.unisa.edu.au/Josh.McCarthy

(previous affiliation: School of Architecture, Landscape Architecture \& Urban Design, The University of Adelaide)

Please cite as: McCarthy, J. (2012). International design collaboration and mentoring for tertiary students through Facebook. Australasian Journal of Educational Technology, 28(5), 755-775. http: / / www.ascilite.org.au/ajet/ ajet28/ mccarthy.html 